\title{
Case Study: LCA Methodology Applied to Materials Management in a Brazilian Residential Construction Site
}

\author{
João de Lassio, ${ }^{1}$ Josué França, ${ }^{2}$ Kárida Espirito Santo, ${ }^{2}$ and Assed Haddad ${ }^{1}$ \\ ${ }^{1}$ Departamento de Construção Civil, Escola Politécnica, Universidade Federal do Rio de Janeiro, Athos da Silveira Ramos 149, \\ Centro de Tecnologia, Bloco D, 207 Cidade Universitária, 21.941-909 Rio de Janeiro, RJ, Brazil \\ ${ }^{2}$ Programa de Pós-Graduação em Engenharia Civil, Universidade Federal Fluminense, Rua Passos da Pátria 156, Bloco D, \\ São Domingos, 24210-020 Niterói, RJ, Brazil
}

Correspondence should be addressed to João de Lassio; jgabriellassio@poli.ufrj.br

Received 30 November 2015; Revised 20 February 2016; Accepted 15 March 2016

Academic Editor: Claudio Mazzotti

Copyright (C) 2016 João de Lassio et al. This is an open access article distributed under the Creative Commons Attribution License, which permits unrestricted use, distribution, and reproduction in any medium, provided the original work is properly cited.

\begin{abstract}
The construction industry is increasingly concerned with improving the social, economic, and environmental indicators of sustainability. More than ever, the growing demand for construction materials reflects increased consumption of raw materials and energy, particularly during the phases of extraction, processing, and transportation of materials. This work aims to help decision-makers and to promote life cycle thinking in the construction industry. For this purpose, the life cycle assessment (LCA) methodology was chosen to analyze the environmental impacts of building materials used in the construction of a residence project in São Gonçalo, Rio de Janeiro, Brazil. The LCA methodology, based on ISO 14040 and ISO 14044 guidelines, is applied with available databases and the SimaPro program. As a result, this work shows that there is a substantial waste of nonrenewable energy, increasing global warming and harm to human health in this type of construction. This study also points out that, for this type of Brazilian construction, ceramic materials account for a high percentage of the mass of a total building and are thus responsible for the majority of environmental impacts.
\end{abstract}

\section{Introduction}

The building construction sector is one of the most dynamic in the Brazilian industry, making significant use of diverse materials in residential, commercial, and industrial construction sites. This construction segment causes environmental, social, and economic impacts on the site and in the region where it takes place, and these impacts reflect from the manufacture and transport of materials, until the execution of a particular construction project [1]. These impacts have caused concern in society, particularly regarding the environment, since they have increased significantly due to growth in the construction sector, which is a major consumer of materials and energy in Brazil. This growth in demand for construction materials directly reflects increased consumption of raw materials and energy, particularly during the phases of extraction, processing, and transportation of materials.

In addition, it is important to take into account that the consequent expansion of waste generation is caused by a surplus of unused materials and demolition leftovers. In large Brazilian cities, the mass of construction and demolition waste ranges from 45 to $70 \%$ of the total mass of solid waste generated, with the great majority coming from residential sector sources. The volume of construction and demolition waste amounts to more than half of a town's solid waste, and most of it is improperly deposited without segregation and management $[2,3]$. In the real-world scenario, it is necessary to reduce environmental impacts in the pursuit of construction sustainability. In order to do so, it is important to develop and specialize supply chains of building materials and to seek sustainable materials that are not harmful to human health and that are durable or reusable, renewable, clean, and affordable [4].

\section{State of the Art and Research}

Traditionally, local materials with low energy costs and low environmental impact were used in the building sector. 
Nowadays, global materials such as cement, aluminum, concrete, and PVC are used, increasing the energy costs and environmental impact. At present, the building sector contributes largely to the global environmental load of human activities: for instance, around $40 \%$ of the total energy consumption in Europe corresponds to this sector. The manufacture, transport, and installation for a building made of materials such as steel, concrete, and glass require a large quantity of energy, even though they represent a small part of the ultimate cost of the building as a whole [5].

The construction industry has become one of the biggest consumers of resources and energy inputs. Indeed, throughout their life cycle, buildings around the world account for approximately $40 \%$ of $\mathrm{CO}_{2}$ emissions, $40 \%$ of natural resource consumption, and approximately $40 \%$ of waste generation. Because of this, the construction industry is sometimes referred to as "the industry of $40 \%$ " [6]. In the United States, for example, buildings account for $39 \%$ of total energy use and $38 \%$ of all carbon dioxide emissions, which confirms this reputation [7]. Analyzing this situation is needed for simultaneous improvement of quality and environmental management in the construction industry, through significant investments in processes, procedures, and technologies. In other words, the construction industry segment must align its success and investments with growing responsibilities towards society in order to engage in adequate and successful sustainable development practices.

In this context, this study aimed to evaluate the environmental impacts of major construction materials in residential buildings, such as steel, cement, ceramic, and wood. Thus, we propose the application of the concept of sustainability in supply chains and life cycles in order to assist in making environmental decisions and contribute to the management of the life of a residential construction project cycle.

The concept of sustainable development, applied to building construction, such as residential buildings, involves aspects related to the choice of materials, the construction methods, and the use, operation, and demolition of buildings. Primarily, this concept focuses on the reduction of $\mathrm{CO}_{2}$ emissions, energy consumption, and the progressive depletion of natural resources by the construction industry. This was shown in a comparative study by Peng and $\mathrm{Wu}[8]$, where the $\mathrm{CO}_{2}$ emissions produced during the construction phase of a building represented $12.60 \%$ of the total emissions of the life cycle, which is the second highest emission load (Figure 1). It is possible to see that most of the carbon was issued during the operational and maintenance phase of the building, and a small percentage of $\mathrm{CO}_{2}$ emissions were consumed in the demolition stage.

In other words, the overall view of the impact on the environment is often not taken into account. Although environmental awareness is increasingly present in the construction industry, the overall view of the impact on the environment is often not taken into account and traditionally has been limited to occasional reflections and short term. In fact, it is essential to develop environmental assessment of building materials in the construction sector. This subject presents a vast field for research, taking into account the full life of the equipment (i.e., to evaluate environmental

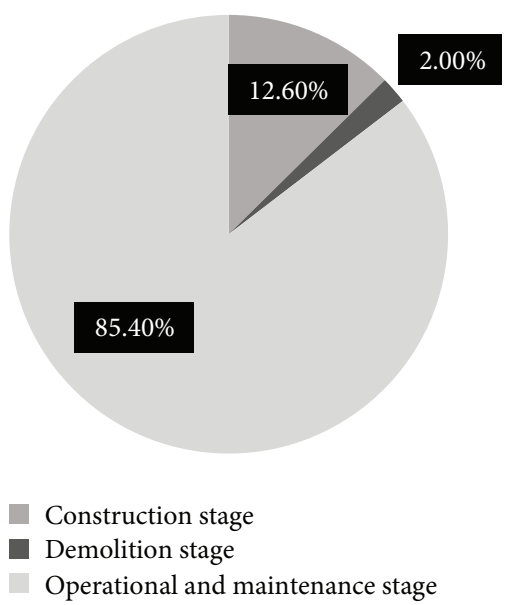

Figure 1: Percentage of $\mathrm{CO}_{2}$ emissions produced in a building life cycle [8].

performance from the production of materials to be used until their final disposal at the end of the useful life of the building) and a wide range of materials available on the market [9].

According to $\mathrm{Wu}$ et al. [10], in the case of building construction, a specific material may be preferable during the construction phase; however, the chosen material may cause problems during the demolition phase due to its handling.

For example, it is assumed that the end-of-life materials are landfilled. Various other disposal alternatives are possible, including incineration, biological treatment, composting, and recycling. Such optimization of end-of-life materials disposal may become increasingly important in the future [10].

That means waste produced globally may cause more negative impacts on the environment. In this context, the life cycle assessment (LCA) is the most effective tool among all available tools. Its practice and current dissemination make it an increasingly efficient and recognized instrument, because it evaluates the impacts from the extraction of raw materials to the final disposal of products by providing knowledge about the different phases.

Previous studies [11-13] have reviewed building LCA tools; however, there are some gaps regarding environmental indicators [14], easily understandable presentation of LCA results to users, and the simplification and adaptation of the LCA to various purposes (e.g., early design phases). The LCA was mainly developed for designing products with low environmental impact. As products, buildings are special, because they have a comparatively long life, often undergo changes (especially offices and other premises), frequently have multiple functions, contain many different components, are locally produced, are normally unique (there are seldom many of the same kind), cause local impact, are integrated with the infrastructure, have unclear system boundaries, and so forth. This implies that making a full LCA of a building is not a straightforward process like for many other consumer products [15]. 


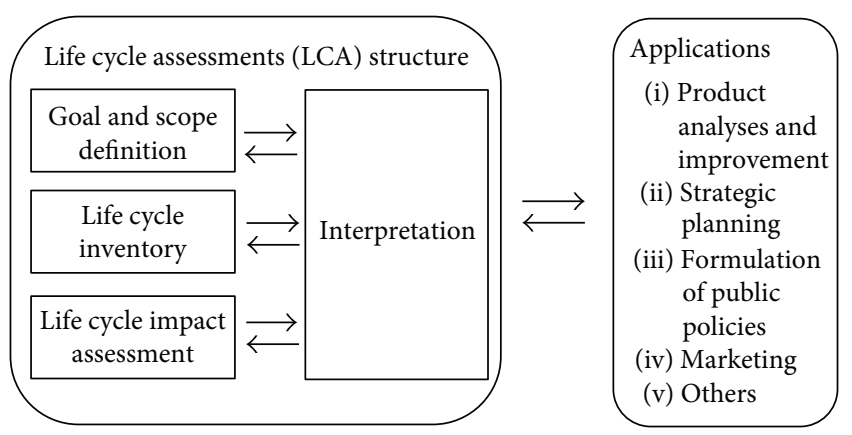

Figure 2: Methodological framework of LCA [23].

In addition, social, economic, and environmental indicators of sustainable development are drawing attention to the construction industry, which is a globally emerging sector and a highly active industry in both developed and developing countries $[16,17]$. LCA methods have been used for the environmental evaluation of product development processes in other industries for a long time, although application to the building construction sector has been state of the art for the last 10 years $[18,19]$. Because the LCA takes a comprehensive, systemic approach to environmental evaluation, there is increasing interest in incorporating LCA methods into building construction decision-making for the selection of environmentally preferable products, as well as for the evaluation and optimization of construction processes [20]. In addition, a growing body of literature is developing, employing LCA methods in the performance evaluation of buildings, building design, and construction practices. However, the LCA literature is fairly fragmented and spread over several national and international publications [21].

\section{Methodology}

In this work, we analyze the environmental impacts of building materials used in the construction of a residence project. We followed the methodological framework of an LCA governed by the international standard ISO 14040, which defined four main phases for the study of LCA, which are interconnected in some way, as shown in Figure 2. First, we defined the goal and scope of the analysis. Second, we built the inventory by quantifying materials and determining the appropriate LCA databases of the materials to be used. Third, we used the SimaPro software to calculate impacts and assess the situation. Fourth, we interpreted and analyzed the results and also revised the study. Finally, we presented conclusions.

The construction site selected is a residential building construction composed of five single family units, each with two floors and targeted to lower-middle class citizens. The site is located in the city of São Gonçalo, Rio de Janeiro, Brazil. This construction was mostly designed and built by the traditional method of construction, with a reinforced frame, ceramic bricks, and mortar. Each residential unit has a living room, kitchen, utility area, bathroom, two bedrooms, garage, and a deep yard, with a total built area of around $56 \mathrm{~m}^{2}$ on average. The land has a total area of $309.00 \mathrm{~m}^{2}$ and a building area of about $280 \mathrm{~m}^{2}$, generating an occupancy rate of $42.38 \%$.

3.1. Life Cycle Assessment. The LCA examines in systemic ways the aspects and environmental impacts of product systems, from the acquisition of raw materials to final disposal, according to the purpose and the field of study stipulated. As a supplement, it can be said that the evaluation quantifies globally and as thoroughly as possible the potential effects of a product on the environment. The approach consists in simultaneously quantifying the flows of materials and energy linked to the operations or activities and the translation of these data into a small number of indicators, measuring their impact on the environment [23].

The knowledge about the differences in the stages of a product or service provides data on its components, constituent materials, and transforming processes. The analysis, evaluation, and interpretation of the results can be directed at identifying potential improvements in relation to the environmental performance of products at different stages of their life cycles, the information to manufacturers and organizations, and even the choice of performance indicators of environmental products. Broadly speaking, this observation may have a multidimensional nature and applicability for improvement, such as the conservation of the environment $[25,26]$.

The application of the LCA covers several areas, such as the industrial segment, community organizations, and certifying entities. In the case of private companies, the goals can be characterized by obtaining ecolabels and certifications, business marketing, compliance with laws, scenario comparison, materials, and products.

The use of the LCA as an environmental management tool began in the 1960s in different forms and with a variety of names. This methodology has evolved, and since the 1990s the term life cycle assessment has been adopted to refer to studies on the environmental life cycle. In fact, in the early 1990s a need emerged for environmental impact studies to include multiple criteria, such as consumption of raw materials and energy, air pollution, and water and waste production, taking into account the set of steps in the life cycle of a product, that is, from manufacture to final disposal, as well as the use phase. However, most of these studies were focused on the areas of energy efficiency, consumption of raw materials, and the final disposal of waste. Nowadays, the assessment includes the entire cycle via the product, process, or activity, encompassing extracting and processing of raw materials; processing, transportation, and distribution, use, reuse, and maintenance; and recycling and final disposal. In its application in the construction industry, the LCA can consider analyses of products in the industry, individual buildings, and groups of buildings [27].

In the actual scenario of sustainability in building construction, several authors have developed studies regarding the LCA in construction, presenting it in a comprehensive way, with very extensive information from the construction sites [21]. Other studies address specific questions involving energy measures on buildings and the comparison between 
construction methods and materials $[28,29]$. In accordance with Rist [30], there are still limitations to the LCA data available for general building materials. However, these limitations are being improved by new tools that are becoming available for research and also by the level of quality of data for statements on environmental products. This study shows that the LCA is a methodology that is useful not only for construction management but also for environmental assessment, taking different approaches.

The selection of building materials was evaluated in the context of the life cycle methodology. Thus, all phases of an LCA methodology set in the regulatory framework were considered. The results of the analysis are presented by means of graphs generated by SimaPro software based on the inventory of each material considered in construction.

\section{Case Study}

The case study presented in this paper is the practical application of the LCA methodology in a real construction site in Brazil, analyzing the quantities of materials consumed and the basic considerations of the most critical inputs in this scenario, such as steel, ceramics, cement, and wood, through the same design and technical recommendations. It is in accordance with regulatory requirements and uses SimaPro software and the LCA methodology, providing results that will be interpreted and analyzed.

4.1. Goal and Scope. The boundary established for the system under study was delimited by extracting, manufacturing, distributing, demolishing, and end of life, excluding all other steps. A significant period of time and impacts related to the consumption of energy and water in the use phase of buildings were excluded from the analysis. The functional unit is the set of features that should be the same when comparing different design options, and for this study we defined a functional unit as one family unit of the five family units of the selected construction site. This functional unit has a living room, kitchen, utility area, bathroom, two bedrooms, garage, and a deep yard, with a total built area of around $56 \mathrm{~m}^{2}$ on average. The objective of this study is to analyze the environmental impacts of the selected functional unit using the LCA methodology to evidence and compare environmental impacts when using different construction materials.

4.1.1. Assessment Objectives. The goal of this assessment is to quantify the flows of materials and energy to the boundaries of a building system and measure these data in order to determine the impact on the environment. Attention is given to this assessment in the impacts that are often associated with construction activity, such as global warming, natural resource consumption, consumption of nonrenewable energy, and harm to human health. Considering that environmental concern is a recent discipline, diffusion studies in this area are essential, especially in Brazil. Thus, this study has as a second goal to achieve a significant public interested in sustainability and ecodesign, presenting them

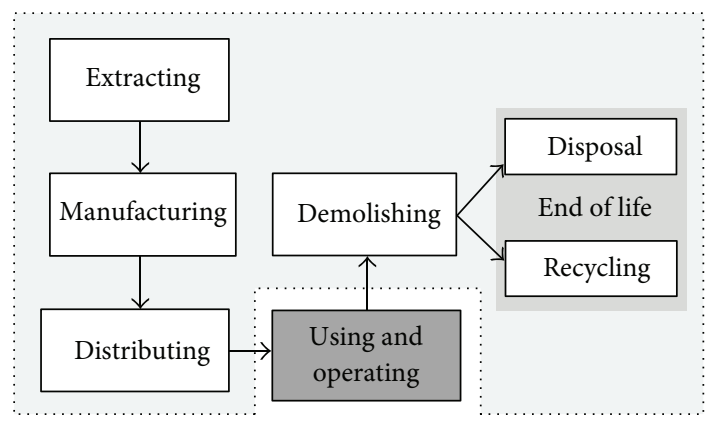

FIGURE 3: Layout of the system boundary [24].

with quantitative results and possibilities of improvement in products and process. Overall, the results presented can be shared with all individuals and organizations interested in this area of study.

4.1.2. Scope. The analysis focused on the foundations of the structure, partition walls, jackets, window frames, and roof of the building in question. The subsystems and their associated materials are as follows:

(i) Foundations: reinforced concrete structure; materials used: cement and steel.

(ii) Structure: reinforced concrete structure; materials used: wood, cement, and steel.

(iii) Masonry: brick blocks and mortar applied; materials used: cement and ceramic.

(iv) Wall covering: tiles, flooring, and mortar applied; materials used: cement and ceramic.

(v) Frames: doors and wood windows; materials used: wood, cement, and steel.

(vi) Roofing: roof with two slopes on ceramic tiles and wooden structure; materials used: wood, ceramic, and steel.

As shown in Figure 3, the boundary established for the system under study was delimited by extracting, manufacturing, distributing, demolishing, and end of life, excluding all other steps. In order to have an objective analysis, infrastructure processes were not taken into account, such as the construction of factory or manufacturing equipment and vehicles necessary for the production, operation, and transport of materials.

The end-of-life phase is featured by disposal, because in Brazil most construction waste is disposed of in landfills. In fact, only about $1 \%$ of rubbish is recycled in Brazil, and the vast majority is disposed of in landfills and vacant lots [24, 31]. On the other hand, one should also consider the effective reuse of some materials and products in the demolition of a building, especially when dealing with frames and other wooden elements. With this, in the end-of-life scenario considered, where industrial landfills and recycling plants will be covered, it is possible to have the following:

(i) Cement and ceramic: $25 \%$ recycled and $75 \%$ landfilled. 
TABLE 1: Quantities of materials [22].

\begin{tabular}{lc}
\hline Material & Quantity $(\mathrm{kg})$ \\
\hline Steel & $5,034.37$ \\
Ceramics & $131,798.13$ \\
Cement & $28,369.30$ \\
Wood & \\
$\quad$ Paraná Pine & $5,853.76$ \\
$\quad$ Peroba-Rosa & $4,197.82$ \\
\hline
\end{tabular}

(ii) Steel and wood: 50\% recycled and 50\% landfilled.

We used the Ecoinvent and 2001 Idemat databases for this study. Regarding the quality of these databases, it is important to emphasize that these databases portray the reality of European construction, which employs high technology, whereas in Brazil most of the buildings are made by craftsman workers and employ low technology [27, 32].

4.2. Life Cycle Inventory. According to ISO 14040 [23], inventory analysis involves data collection and calculation procedures to quantify relevant inputs and outputs of a product system. These inputs and outputs may include the use of resources and releases to air, water, and land associated with the system. Interpretations may be drawn from these data, depending on the goals and scope of the LCA. These data also constitute the input to the LCA. The process of conducting an inventory analysis is iterative. As data are collected and more is learned about the system, new data requirements or limitations may be identified that require a change in the data collection procedures so that the goals of the study will still be met. Sometimes, issues may be identified that require revisions to the goal or scope of the study.

4.2.1. Inventory. At this stage, the identification of nonelementary streams and quantification of elementary streams occur. These differ in that they are inputs and outputs of existing processes in the different stages of the life cycle, occurring between the agents and the environment. In other words, this phase documents data inputs and outputs system reported in the study, which was performed in SimaPro software.

4.2.2. Data Collection. Quantification of the materials was based, in general, on the 13th edition of TCPO (Tables for Compositions of Prices for Budgets), which is considered one of the reliable databases in Brazilian building construction [22]. The amounts of each material can be observed in Table 1.

The life cycles of materials were modeled on flows of inputs and outputs of the processes, as shown in Figure 4. Note that the inputs and outputs were based on the databases used in this work.

The transportation model used for all construction phases is the road transportation, once this mode of transport is easy to reach and the area next to the site has a large road system connecting the country. In the manufacturing phase, the construction site is considered the same location for construction and extraction of raw materials. For the

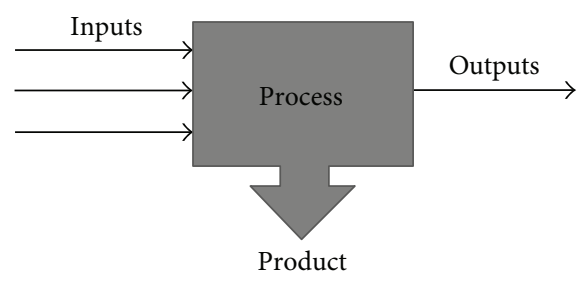

FIgURE 4: Schematic of the modeling life cycle [24].

distribution phase, it was considered an average of the distances between existing suppliers nearby the construction site, which resulted in a range of $10 \mathrm{~km}$. At the end-of-life stage, only the scenarios in which the waste is destined for a landfill or to be processed for recycling are taken into account, having displacements of $12 \mathrm{~km}$ and $55 \mathrm{~km}$, respectively.

4.3. Life Cycle Impact Assessment. According to ISO 14040 [23], the LCA determines the environmental impacts of products, processes, or services through production, usage, and disposal. It is a systematic set of procedures for compiling and examining the inputs and outputs of materials and energy and the associated environmental impacts directly attributable to the functioning of a product or service system throughout its life cycle.

4.3.1. Assessment of Impacts. The assessment of impacts translates consumption and waste identified in the inventory phase environmental impacts, such as the greenhouse effect, hole in the ozone layer, smog, acid rain, eutrophication, and toxicity. To manage those elements, the method of calculation IMPACT2002+ was used, because it proposes a combination of classical approaches (midpoint) and targeted to the damage (endpoint), thus grouping the strengths of methods, such as IMPACT2002, Eco-Indicator 99, CML 2000, and IPCC. Further observation categories were those related to global warming, natural resource consumption, consumption of nonrenewable energy, and toxicity to human health.

The IMPACT 2002+ methodology combines midpoint/ damage approaches linking all types of life cycle inventory results via 14 midpoint categories (human toxicity, respiratory effects, ionizing radiation, ozone layer depletion, photochemical oxidation, aquatic ecotoxicity, terrestrial ecotoxicity, terrestrial acidification/nitrification, aquatic acidification, aquatic eutrophication, land occupation, global warming, nonrenewable energy, and mineral extraction) to 4 damage categories (human health, ecosystem quality, climate change, and resources) [33].

The results presented in this paper were based on the comparison and analysis of the materials used in the functional unit of one family unit in the selected construction site of this study. In Figure 5, through the type of characterization, the translation of incoming and outgoing flows in the impact IMPACT2002+ method version 2.05 is presented.

The most significant impacts are life cycles of steel, cement, and ceramics. In 2 of the 15 analyzed impact categories, carcinogens (toxicity to human health) and mineral extraction (consumption of nonrenewable energy), the life 


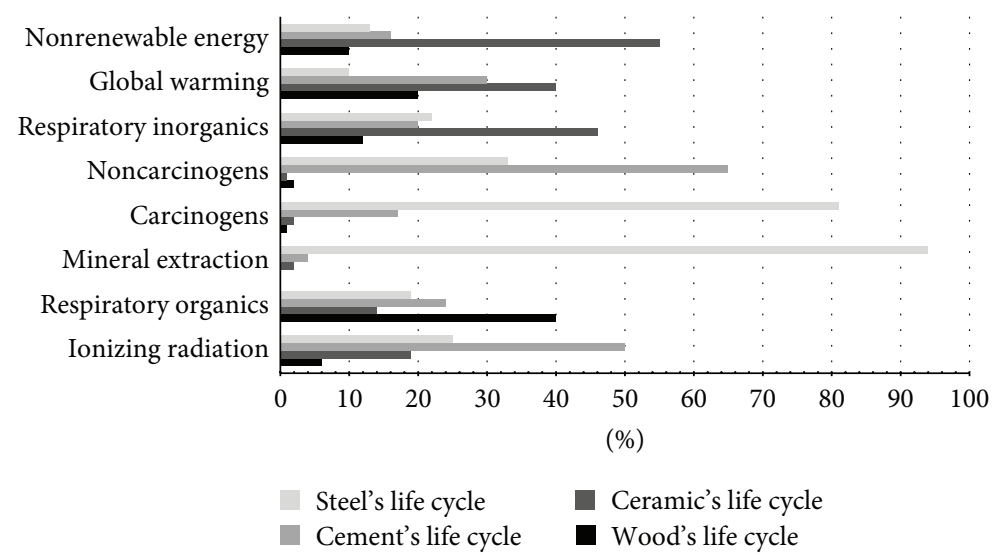

FIGURE 5: Comparison of the life cycles of selected materials, IMPACT2002+ method, and characterization [24].

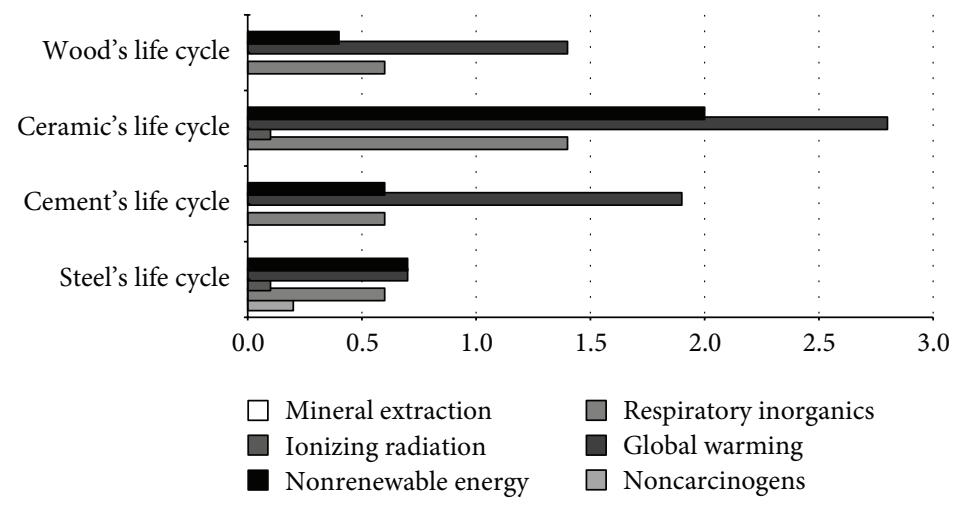

FIgURE 6: Comparison of the life cycles of selected materials, IMPACT2002+ method, and single score [24].

cycle of steel is almost exclusively characterized as the most significant agent. Global warming and the use of nonrenewable energy, which are somewhat interconnected, have the life cycle of ceramics as the main agent. The noncarcinogen categories and ionizing radiation were those in which cement showed greater expressiveness. Steel, concrete, and ceramics are characterized as major causes by impacts. Applying the method of standardization by the IMPACT2002+ methodology, it is observed that the most significant impacts, taking into account all materials, are related to global warming and the use of inorganic nonrenewable and respiratory energy (air emissions of $\mathrm{NO}_{X}$ and $\mathrm{SO}_{2}$ ).

As shown in Figure 6, when applied to the single score, global warming has the most obvious impact on the life cycles of all materials considered, followed by the use of inorganic nonrenewable energy and breathing. The functional unit considered is one family unit in the selected construction site of this study.

\subsection{Interpretation}

4.4.1. Analysis of Data. The final phase of the LCA, inventory results, and the assessment of life cycle impacts are summarized and discussed to reach a decision based on findings and recommendations as the definition of objectives and scope [25]. Based on that and analyzing the data and results of those materials life cycle, the most severe impacts are related to global warming, consumption of nonrenewable energy, and toxicity to human health. This global warming impact is more representative by the life cycle of ceramics. In fact, global warming occurs largely by burning fossil fuels, which are used in manufacturing processes and in distribution, transport, and utilization. Moreover, it is important to note that the ceramic material was in greater quantities, corresponding to about $75 \%$ by weight of the materials considered for the construction of the site studied, as shown in Figure 7, so this higher impact was expected.

In the context of global warming, the life cycle of cement also stands out. This can be explained by the natural process of manufacture of clinker, called calcinations, that is responsible for significant emissions of carbon dioxide, which contributes significantly to global warming. Regarding toxicities, considering the effects of steel and cement effects in human health, the most significant impacts were cancer and respiratory inorganic substances. The former is, for the most part, from the life cycle of steel, and the latter is from the life cycle of pottery. Despite this high impact, steel and cement are key materials that are difficult to replace in the traditional system of construction, especially in Brazil. 


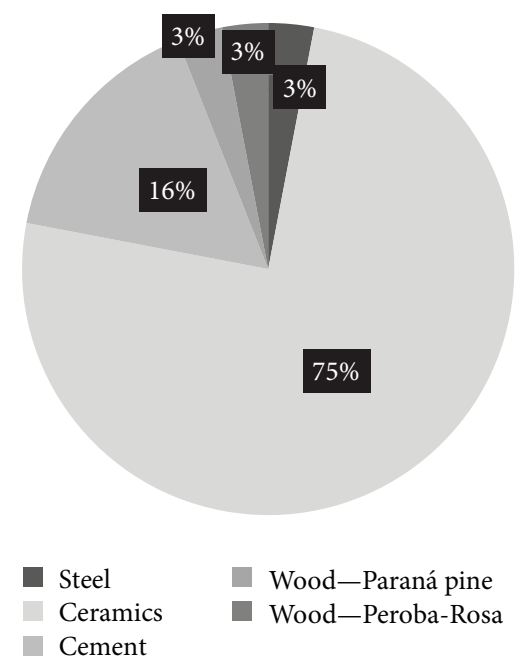

FIgURE 7: Composition of building materials (kg) [24].

Taking a closer look at the impacts, it is possible to note that ceramic stood out as the most responsible for the impacts, perhaps because it requires a larger amount of mass between materials. Moreover, the life cycles of cement and steel also had significant impacts, most often related to toxic substances. Wood does not present greater consumption of fossil fuels than the other materials studied, once it does not need large dislocations during the construction phases. However, analyzing the dislocations in the global supply chain, cement and steel consume more fossil fuels than ceramics, and yet, the ceramic has higher total intake compared to cement and steel.

4.5. Results. The results of our study show that steel, cement, and ceramic material are the most responsible for environmental impacts. In the case of ceramic materials, a larger amount of mass, compared to other materials, explains their greater accountability for the impacts, especially because most of Brazilian constructions use several quantities of coating ceramics and bricks.

In addition, the results show three impacts as the most important impacts of the life cycles of the materials analyzed: substantial expenditure of nonrenewable energy, rise of global warming, and harm to human health.

\section{Conclusions}

In order to consider the environmental impacts of the most essential building materials in the segment of residential building construction and to promote the concept of sustainability through the LCA methodology, this study included a simplified analysis of the phases of the entire chain of steel, ceramic, cement, and wood employed in a building specification. In this regard, this study highlighted some critical points, such as the considerable consumption of fossil fuels and nonrenewable energy, which contributes to global warming and toxicity to human health. The extraction of natural resources and their scarcity, though often mentioned, have not presented a significant influence compared to other impacts.

As a base of support for future decision-making, this study shows a need for action in the chain of production of steel, cement, and ceramic materials. Regarding ceramic materials, it is necessary to conduct complementary research in order to analyze and study the possibility of replacing this material or structural system. These actions should also cover the end of life of the materials, once there is a huge amount of waste on vacant land without adequate storage and treatment, contributing to raise the impacts, as featured by this study. In addition, the results presented by this study contribute to the promotion of the LCA methodology in the construction industry, treating problems; disseminating, analyzing, and interpreting results; and discussing solutions. Furthermore, this study also intends to assist the building construction industry to achieve sustainable development and environmental protection at all stages of a construction.

Even though isolation materials are well known for their high energy demand and toxicity in the manufacturing phase, these materials are not within the scope of this study. Brazilian construction has a unique situation regarding climate, construction typology, physical resources, raw materials, and tradition, so for most of the country no isolation is used other than ceramic tiles for masonry.

In light of our results, we recommend that building designers and planners review the usage of ceramic materials in their projects, aiming to reduce ceramic impacts in all phases of a building construction. This may be observed during the design phase and determination of construction methods in order to minimize the weight of ceramic materials in the whole process.

A recommendation for future work is to consider the use phase of the building in LCA analysis, once this phase involves the inputs needed for the remodeling and maintenance of the building. Furthermore, it would be interesting to consider a wider range of materials such as glass and plastic. In this context, LCA methodology provides the important possibility of a comparative analysis of materials and products in a construction segment that performs the same functions. Besides, decision-making is facilitated by comparative results of impacts and can therefore justifiably substitute materials and products. Further studies comparing different materials and products that are applied to the same uses should assess their life cycles in order to identify serious concerns in the production chains of these materials.

Facing the aggressive and challenging needs of a construction business, it is important and somewhat imperative to reach sustainable development and environmental protection in all phases of any construction. In this context, the LCA contributes not only to environmental and sustainability issues but also to business continuity. Analyzing Brazilian building technologies, the LCA shows that ceramics are heavily used, providing an opportunity to seek different and new materials to be used in replacement. Additionally, Brazilian construction techniques, compared to European and American techniques, are mostly manual, done by craftsman workers, and employ low technology; this scenario shows a great opportunity of development and evolution for 
Brazilian construction techniques. End-of-life scenarios play an important role in LCA studies, but the lack of reliable data prevents proper development of such studies, mainly because Brazil uses LCA databases of international data due to the unavailability of domestic LCA databases. Improvements in data collection and the construction of databases are highly recommended.

\section{Competing Interests}

The authors declare that there are no competing interests regarding the publication of this paper.

\section{Acknowledgments}

Assed Haddad acknowledges a grant from the CNPq (Brazilian National Council for Scientific and Technological Development).

\section{References}

[1] Brazil. Standard Methodology for Developing Life Cycle Inventories of Brazilian Industry-Project, SICV Brazil-System Life Cycle Inventories Brazil, Brasilia, Brazil, 2011 (Portuguese).

[2] E. Santiago, Use of EVA and RCD aggregates to obtain light concretes [M.S. thesis], Feira de Santana State University, Feira de Santana, Brazil, 2008 (Portuguese).

[3] G. O. D. Azevedo, A. M. Kiperstok, and L. R. Santos, "Construction waste in Salvador: the paths to sustainable management," Engenharia Sanitária e Ambiental, Federal University of Bahia, vol. 11, no. 1, pp. 65-72, 2006 (Portuguese).

[4] K. M. S. P. Condeixa, Comparison of the construction materials through the life cycle assessment: drywall and masonry systems [M.S. thesis], Fluminense Federal University, Niterói, Brazil, 2013 (Portuguese).

[5] I. Z. Bribián, A. A. Usón, and S. Scarpellini, "Life cycle assessment in buildings: state-of-the-art and simplified LCA methodology as a complement for building certification," Building and Environment, vol. 44, no. 12, pp. 2510-2520, 2009.

[6] S. Lasvaux, Study of a simplified model for the life cycle analysis of buildings [M.S. thesis], Paris Institute de Technologie, 2010 (French).

[7] US EPA. United States Environmental Protection Agency, Buildings and Their Impact on the Environment: A Statistical Summary, Archive Document, US EPA, 2009.

[8] C. Peng and X. Wu, "Case study of carbon emissions from a building's life cycle based on BIM and Ecotect," Advances in Materials Science and Engineering, vol. 2015, Article ID 954651, 15 pages, 2015.

[9] G. Grigoletti, Characterization of environmental impacts of red ceramic industries of the state of Rio Grande do Sul [M.S. thesis], Rio Grande do Sul Federal University, Porto Alegre, Brazil, 2001 (Portuguese).

[10] H. J. Wu, Z. W. Yuan, L. Zhang, and J. Bi, "Life cycle energy consumption and $\mathrm{CO} 2$ emission of an office building in China," International Journal of Life Cycle Assessment, vol. 17, no. 2, pp. 105-118, 2012.

[11] S. Nibel, T. Luetzkendorf, M. Knapen, C. Boonstra, and S. Moffat, "Annex 31: energy-related environmental impact of buildings," Technical Synthesis Report, International Energy Agency, 2005, http://www.iisbe.org/annex31/index.html.

[12] A. Haapio and P. Viitaniemi, "A critical review of building environmental assessment tools," Environmental Impact Assessment Review, vol. 28, no. 7, pp. 469-482, 2008.

[13] M. Erlandsson and M. Borg, "Generic LCA-methodology applicable for buildings, constructions and operation services-today practice and development needs," Building and Environment, vol. 38, no. 7, pp. 919-938, 2003.

[14] J. A. Todd, D. Crawley, S. Geissler, and G. Lindsey, “Comparative assessment of environmental performance tools and the role of the Green Building Challenge," Building Research and Information, vol. 29, no. 5, pp. 324-335, 2001.

[15] I. Z. Bribián, A. V. Capilla, and A. A. Usón, "Life cycle assessment of building materials: comparative analysis of energy and environmental impacts and evaluation of the eco-efficiency improvement potential," Building and Environment, vol. 46, no. 5, pp. 1133-1140, 2011.

[16] O. Ortiz, F. Castells, and G. Sonnemann, "Sustainability in the construction industry: a review of recent developments based on LCA," Construction and Building Materials, vol. 23, no. 1, pp. 28-39, 2009.

[17] U. Scbi, Sustainable Building and Construction Initiative: Information Note, DTIE, Paris, France, 2006.

[18] A. Singh, G. Berghorn, S. Joshi, and M. Syal, "Review of lifecycle assessment applications in building construction," Journal of Architectural Engineering, vol. 17, no. 1, pp. 15-23, 2011.

[19] M. Buyle, J. Braet, and A. Audenaert, "Life cycle assessment in the construction sector: a review," Renewable and Sustainable Energy Reviews, vol. 26, pp. 379-388, 2013.

[20] F. Asdrubali, C. Baldassarri, and V. Fthenakis, "Life cycle analysis in the construction sector: guiding the optimization of conventional Italian buildings," Energy and Buildings, vol. 64, pp. 73-89, 2013.

[21] L. F. Cabeza, L. Rincón, V. Vilariño, G. Pérez, and A. Castell, "Life cycle assessment (LCA) and life cycle energy analysis (LCEA) of buildings and the building sector: a review," Renewable and Sustainable Energy Reviews, vol. 29, pp. 394-416, 2014.

[22] TCPO, Tables for Compositions of Prices for Budgets, PINI, Rio de Janeiro, Brazil, 13th edition, 2008 (Portuguese).

[23] ISO, "Environmental management-life cycle assessmentprinciples and framework," ISO 14040, International Organization for Standardization, 2006.

[24] J. G. G. de Lassio, The Application of Program SIMAPRO to Evaluate the Life Cycles of Building Materials Construction: A Case Study of a Condominium, Graduation, Federal University of Rio de Janeiro, Civil Engineer Department, 2013 (Portuguese).

[25] B. L. C. Costa, Quantificação das emissões de $\mathrm{CO}_{2}$ geradas na produção de materiais utilizados na construção civil no Brasil [M.S. thesis], COPPE, Universidade Federal do Rio de Janeiro, 2012.

[26] ISO, "Environmental management-life cycle assessmentrequirements and guidelines," ISO 14044, International Organization for Standardization, 2006.

[27] M. M. Khasreen, P. F. G. Banfill, and G. F. Menzies, "Lifecycle assessment and the environmental impact of buildings: a review," Sustainability, vol. 1, no. 3, pp. 674-701, 2009.

[28] C. Muñoz, C. Zaror, G. Saelzer, and A. Cuchí, "Estudio del flujo energético en el ciclo de vida de una vivienda y su implicancia en las emisiones de gases de efecto invernadero, durante la fase de construcción Caso Estudio: Vivienda Tipología Social. Región 
del Biobío, Chile," Revista de la Construcción, vol. 11, no. 3, pp. 125-145, 2012.

[29] K. Condeixa, A. Haddad, and D. Boer, "Life cycle impact assessment of masonry system as inner walls: a case study in Brazil," Construction and Building Materials, vol. 70, pp. 141-147, 2014.

[30] T. Rist, A path to BIM-based LCA for whole-buildings [M.S. thesis], Norwegian University of Science and Technology, Trondheim, Norway, 2011.

[31] J. R. Gonçalves, O Dia, Vida e Meio Ambiente, Centre for Construction Waste Recycling Reference and Demolitions. CRCD, 2012 (Portuguese).

[32] K. A. Costa, The use of life cycle assessment in the decisionmaking process on sustainability in the construction industry in building sub-sector [DSc thesis], Fluminense Federal University, Niterói, Brazil, 2012 (Portuguese).

[33] O. Jolliet, M. Margni, R. Charles et al., "IMPACT 2002+: a new life cycle impact assessment methodology," The International Journal of Life Cycle Assessment, vol. 8, no. 6, pp. 324-330, 2003. 


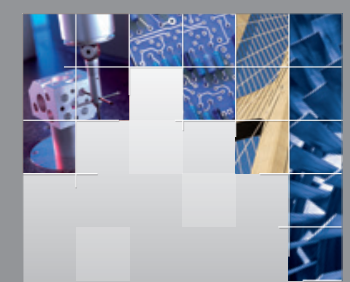

\section{Enfincering}
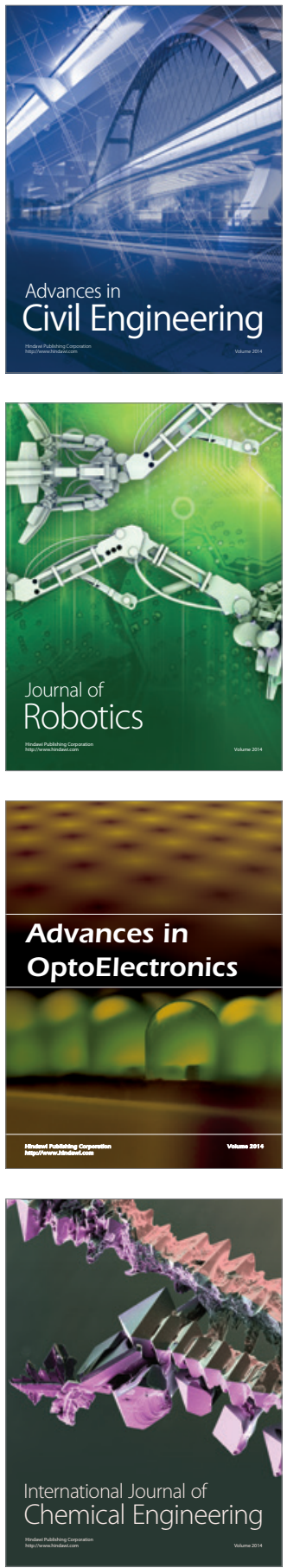

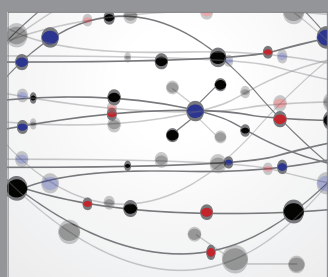

The Scientific World Journal

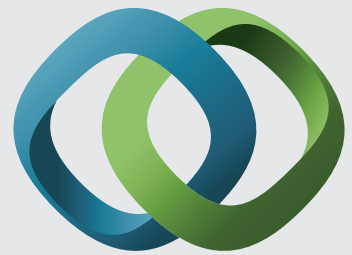

\section{Hindawi}

Submit your manuscripts at

http://www.hindawi.com
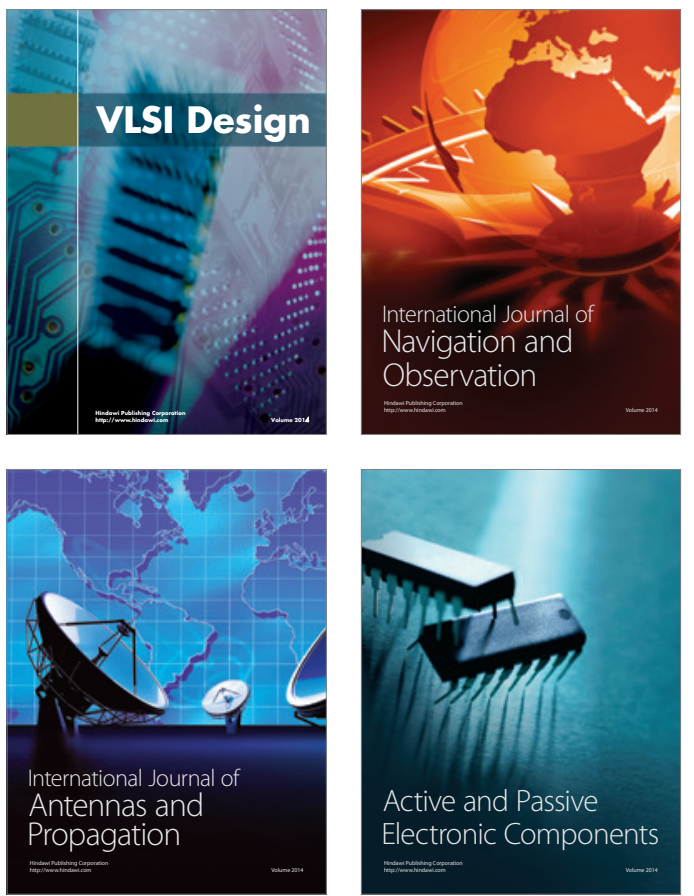
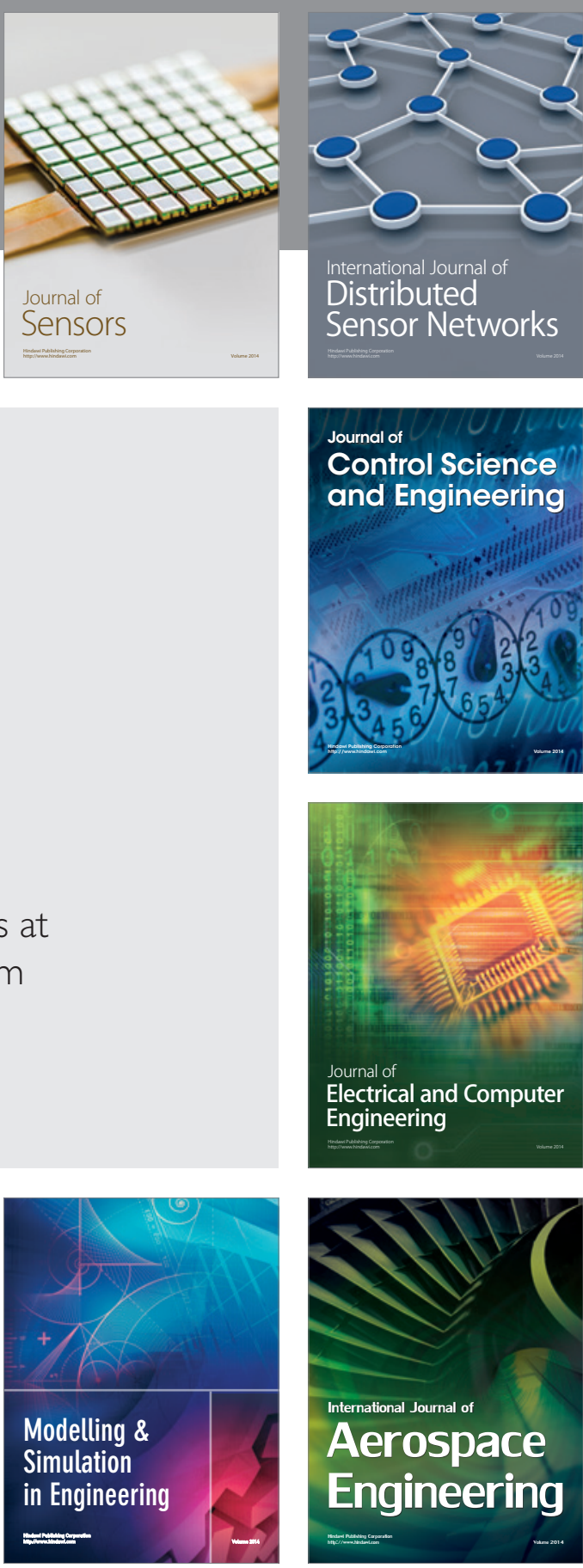

International Journal of

Distributed

Sensor Networks

Journal of

Control Science

and Engineering
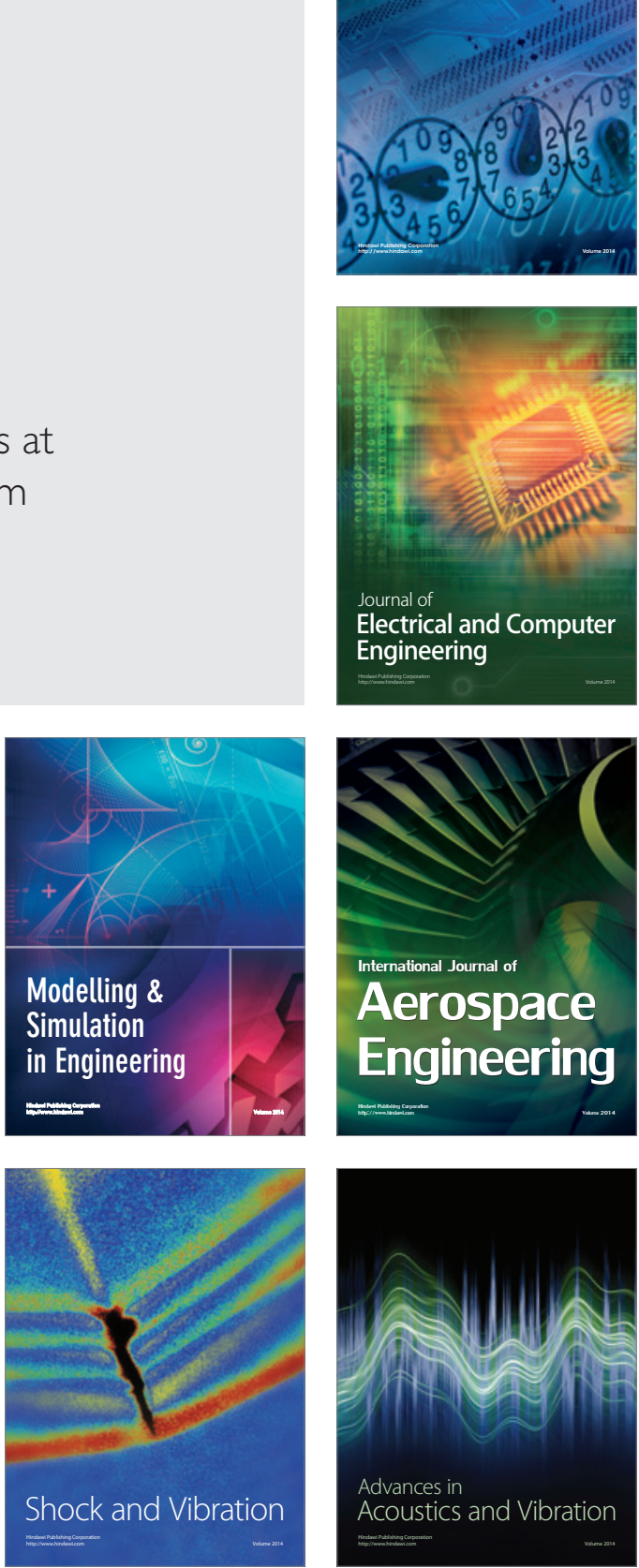